\title{
New Configuration of Handset MIMO Antenna for LTE 700 Band Applications
}

\author{
Byeonggwi Mun, ${ }^{1}$ Frances J. Harackiewicz, ${ }^{2}$ Byeongkwan Kim, ${ }^{1}$ Hyunho Wi, \\ Jonghyun Lee, ${ }^{1}$ Myun-Joo Park, ${ }^{1}$ Changwon Jung, ${ }^{3}$ and Byungje Lee ${ }^{1}$ \\ ${ }^{1}$ Department of Wireless Communications Engineering, Kwangwoon University, 447-1 Wolgye-Dong, Nowon-Gu, \\ Seoul 139-701, Republic of Korea \\ ${ }^{2}$ Department of Electrical and Computer Engineering, Southern Illinois University Carbondale, Carbondale, IL 62901, USA \\ ${ }^{3}$ Graduate School of NID Fusion Technology, Seoul National University of Technology, 172 Gongneung-2 Dong, Nowon-Gu, \\ Seoul 139-743, Republic of Korea
}

Correspondence should be addressed to Byungje Lee; bj_lee@kw.ac.kr

Received 15 February 2013; Accepted 12 April 2013

Academic Editor: Yuan Yao

Copyright (C) 2013 Byeonggwi Mun et al. This is an open access article distributed under the Creative Commons Attribution License, which permits unrestricted use, distribution, and reproduction in any medium, provided the original work is properly cited.

A compact handset multiple-input multiple-output (MIMO) antenna for long-term evolution (LTE) $700 \mathrm{band}$ (746 787 MHz) applications is proposed. The proposed antenna consists of two symmetrical PIFAs. Without the usage of any additional coupling elements between closely mounted antennas, a high isolation $(>15 \mathrm{~dB})$ and a low enveloped correlation coefficient $($ ECC $<0.35)$ are achieved by the optimum location and arrangement of MIMO antenna elements.

\section{Introduction}

The long term evolution (LTE) standard has attracted attention as the fourth generation of mobile communications technology to provide better mobile broadband and multimedia services. Multiple-input multiple-output (MIMO) operation of the LTE system has become a prerequisite to enhance data reliability, channel capacity, and network coverage in multipath environments using multiple antennas without additional power [1]. Since more than two neighboring antennas should be designed within the very limited spaces available in the mobile handsets, achieving high isolation and a low enveloped correlation coefficient (ECC) between closely spaced antennas is very important. A number of studies has been conducted on improving isolation by cutting slots or slits in the ground plane $[2,3]$ and using the ground wall among radiators and a T-shaped short strip [4]. Suspended neutralization line or neutralizing structures have been used for the enhancement of isolation as well [5-9]. However, applying these techniques to LTE MIMO antennas at $700 \mathrm{MHz}$ has become a serious technical challenge, because the ground plane requires modification, and there is no sufficient space to embed additional elements between closely packed antennas. In this paper, we present a promising design of a handset antenna comprising a main antenna for the GSM850/900 $(824 \sim 960 \mathrm{MHz})$ and DCS/PCS $(1.71 \sim 1.99 \mathrm{GHz})$ bands and an auxiliary antenna covering the LTE $700(746 \sim 787 \mathrm{MHz})$ band to perform the MIMO operation. High isolation can be achieved by collinearly arranging the $E$-field directions of LTE MIMO antennas in the near-field region, because a collinearly arranged antenna has a lower mutual impedance than that of a broadside arranged antenna [10]. Moreover, low ECC is achieved by the pattern diversity technique, with LTE MIMO antennas symmetrically located on the top sides of the ground plane.

\section{LTE MIMO Antenna Simulation}

Figure 1 shows the proposed compact LTE MIMO antenna. The overall dimensions of the proposed antenna are $5 \times$ $35 \times 6 \mathrm{~mm}^{3}$, and the size of the ground plane is $60 \times$ $110 \times 1 \mathrm{~mm}^{3}$. As shown in Figure 1(a), the proposed PIFA structure antennas are printed on FR4 substrate $\left(\varepsilon_{r}=4.4\right)$ and 


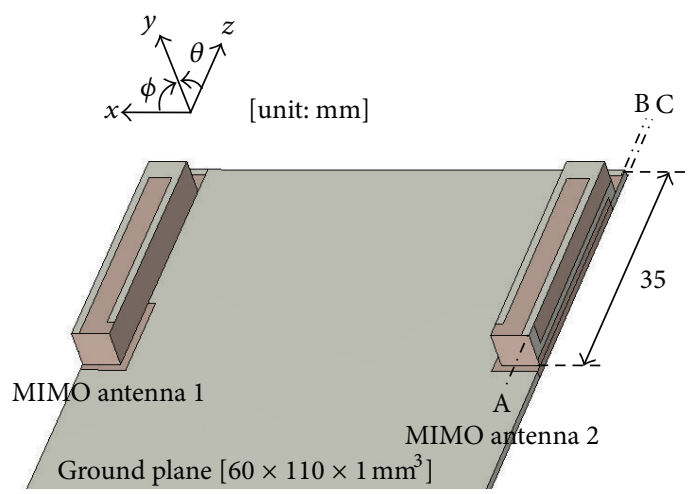

-. - Folded line

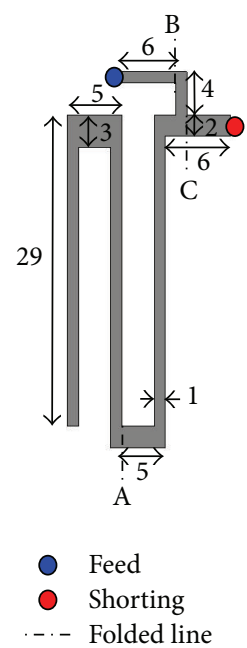

(b)

FIgURE 1: Geometry of the proposed LTE MIMO antenna; (a) overall view and (b) detailed view of antenna element.

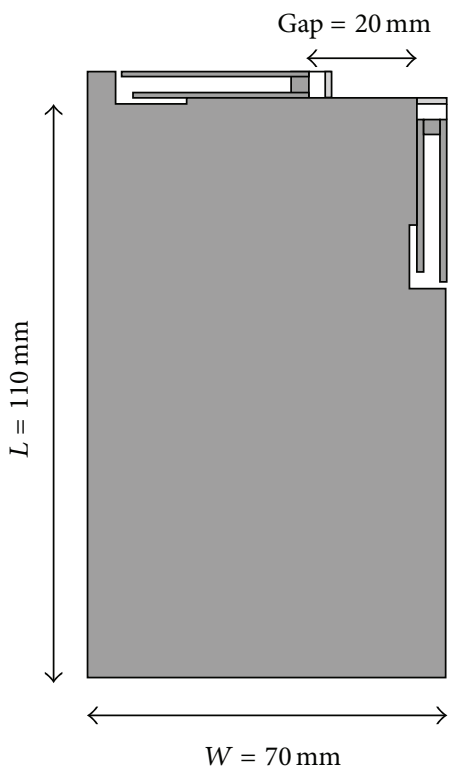

(a)

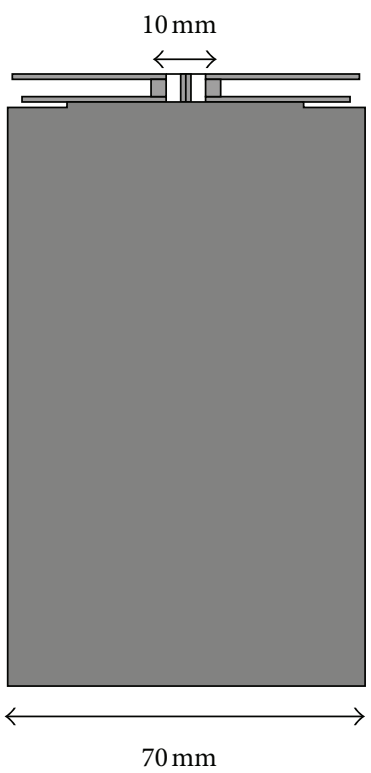

(b)

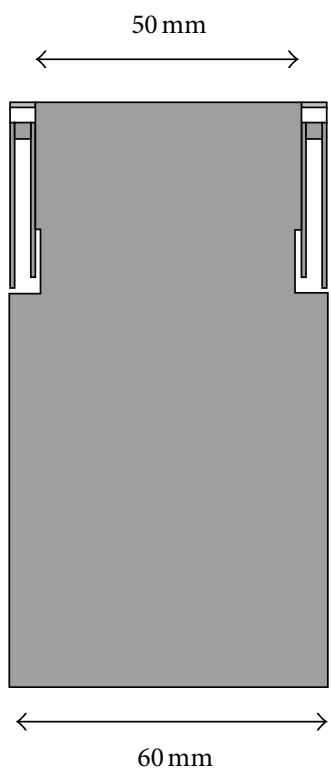

(c)

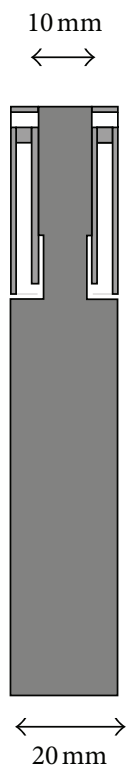

(d)

Figure 2: Antenna location and arrangement; (a) case 1, (b) case 2, (c) case 3, and (d) case 4.

symmetrically arranged on the top sides of the ground plane. The distance between the two PIFAs is $50 \mathrm{~mm}\left(\approx 0.013 \lambda_{0}\right)$. To achieve high isolation and low ECC without any additional coupling structures and cancel out the existing mutual coupling, an optimum antenna location and arrangement are proposed. In general, when two linearly polarized antennas are located orthogonally to each other, they can provide polarization diversity by reducing the mutual coupling, so that high isolation and low ECC can be achieved between them. However, this technique does not work very well for handset antennas at lower frequencies such as the LTE 700 band $(746 \sim 787 \mathrm{MHz})$ because their ground sizes are usually much smaller than their wavelength $\left(\lambda_{0}=429 \mathrm{~mm}\right)$. Therefore, it is necessary to apply a novel technique for the LTE MIMO handset antenna design. The first step in the LTE MIMO antenna design is deciding the location of antenna elements. The top side of the ground plane is an attractive region for mobile handset applications because it is relatively easy to apply pattern diversity when the size of the ground plane is much smaller than the wavelength. The second step is deciding how to arrange antenna elements. In the near-field region, mutual coupling can be suppressed more effectively when the E-field directions of two antennas are arranged collinearly with each other, compared with the broadside 

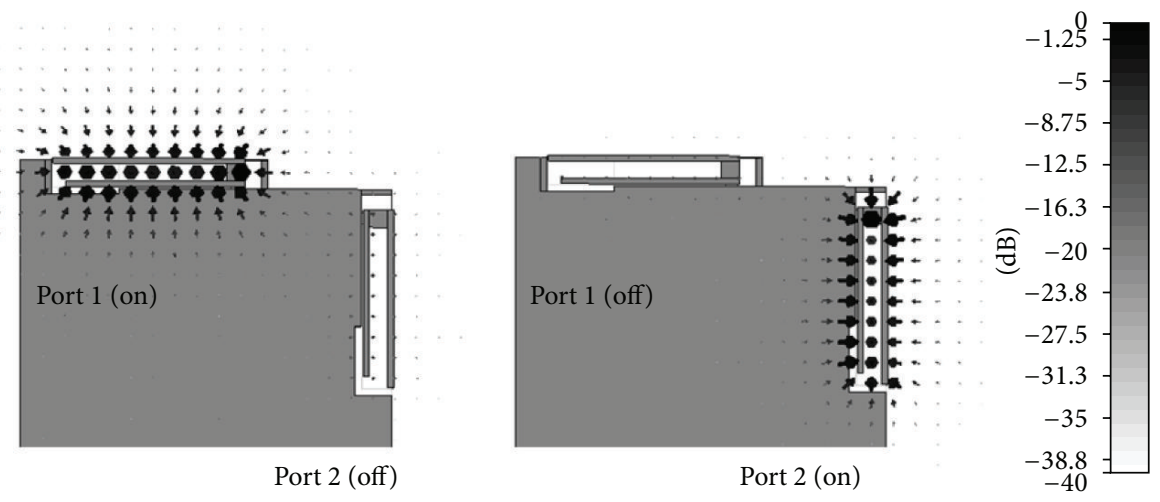

(a)

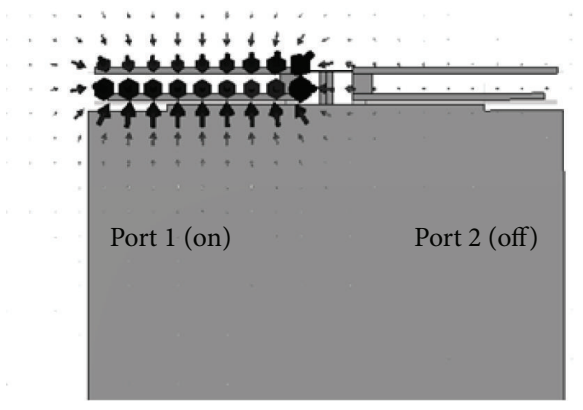

(b)

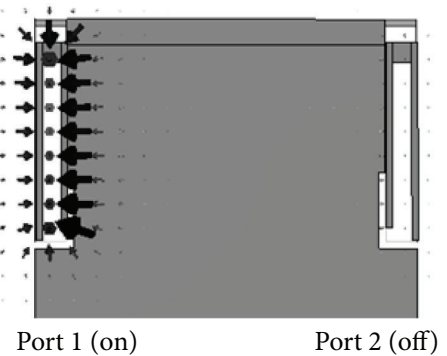

(c)
Port 1 (on)

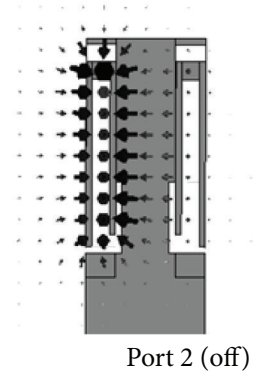

(d)

FIGURE 3: E-field distribution in the near-field region; (a) case 1, (b) case 2, (c) case 3, and (d) case 4.

arrangement of the E-field directions [10]. This proposed method is verified by four cases of antenna arrangementscase 1: perpendicular, case 2: broadside, and cases 3 and 4: collinear-as shown in Figure 2. These are divided into the perpendicular, broadside, and collinear arrangements by the $E$-field distribution as shown in Figure 3. Figure 4 shows that the perpendicular (case 1) and collinear arrangements (cases 3 and 4 ) give higher isolation (magnitude of $S_{21}$ in $\mathrm{dB}$ ) than that of the broadside arrangement (case 2). However, the collinearly arranged MIMO antenna in case 3 only gives the lowest ECC $(<0.19)$, which is less than the recommended value [11] of 0.5 , as shown in Table 1 . This is due to the MIMO antenna in case 3 achieving better pattern diversity in the farfield region than the MIMO antenna in case 1, where the two antennas are physically perpendicular to each other. The ECC shown in Table 1 is obtained by using the far-field radiation patterns [12], as shown in (1), where the incident wave is assumed as a uniform environment $(P(\theta, \phi)=1)$ :

$$
\begin{aligned}
& \operatorname{ECC}\left(\rho_{e}\right) \\
& =\frac{\left|\int_{0}^{2 \pi} \int_{0}^{\pi} E_{1}^{*}(\theta, \phi) \cdot E_{2}(\theta, \phi) \cdot P(\theta, \phi) \sin (\theta) d \theta d \phi\right|^{2}}{\left[\begin{array}{l}
\left(\int_{0}^{2 \pi} \int_{0}^{\pi} E_{1}^{*}(\theta, \phi) \cdot E_{1}(\theta, \phi) \cdot P(\theta, \phi) \sin (\theta) d \theta d \phi\right) \\
\cdot\left(\int_{0}^{2 \pi} \int_{0}^{\pi} E_{2}^{*}(\theta, \phi) \cdot E_{2}(\theta, \phi) \cdot P(\theta, \phi) \sin (\theta) d \theta d \phi\right)
\end{array}\right]}
\end{aligned}
$$

where $E_{1,2}(\theta, \phi)$ is the electric field pattern of antennas 1 and 2 , respectively, and $P(\theta, \phi)$ is the incident field angular density function.

\section{Main/MIMO Antenna Design and Measurement}

Based on the simulation results to find the optimum location and arrangement of the LTE 700 band MIMO antenna, the main antenna covering the GSM850/900 bands (824 $960 \mathrm{MHz})$ and DCS/PCS bands $(1.71 \sim 1.99 \mathrm{GHz})$ and the MIMO antenna (case 3 in Figure 2(c)) covering the LTE 700 band $(746 \sim 787 \mathrm{MHz})$ are designed and measured. Figure 5 shows the structure of the proposed main antenna and MIMO antenna. The compact main antenna mounted on a ground plane $60 \times 110 \times 1 \mathrm{~mm}^{3}$ in size consists of the PIFA structure with a capacitively coupled feed [13]. Its overall dimensions are $60 \times 5 \times 6 \mathrm{~mm}^{3}$, and it is printed on a multilayer consisting of FR4 (thickness $=1 \mathrm{~mm}$ ) and foam (thickness $=5 \mathrm{~mm})$ substrates. Each LTE MIMO antenna $(5 \times$ $35 \times 6 \mathrm{~mm}^{3}$ ) is located on top sides of the ground plane with collinearly arranged $E$-fields in the near-field region.

Figure 6 shows the measured $S$-parameters of the proposed antenna. The proposed antenna (VSWR $<3$ ) covers the LTE 700 band (746 787 MHz), GSM850/900 bands (824 $960 \mathrm{MHz})$, and DCS/PCS bands (1.71 1.99 GHz). Although the main antenna and MIMO antennas are embedded in a 


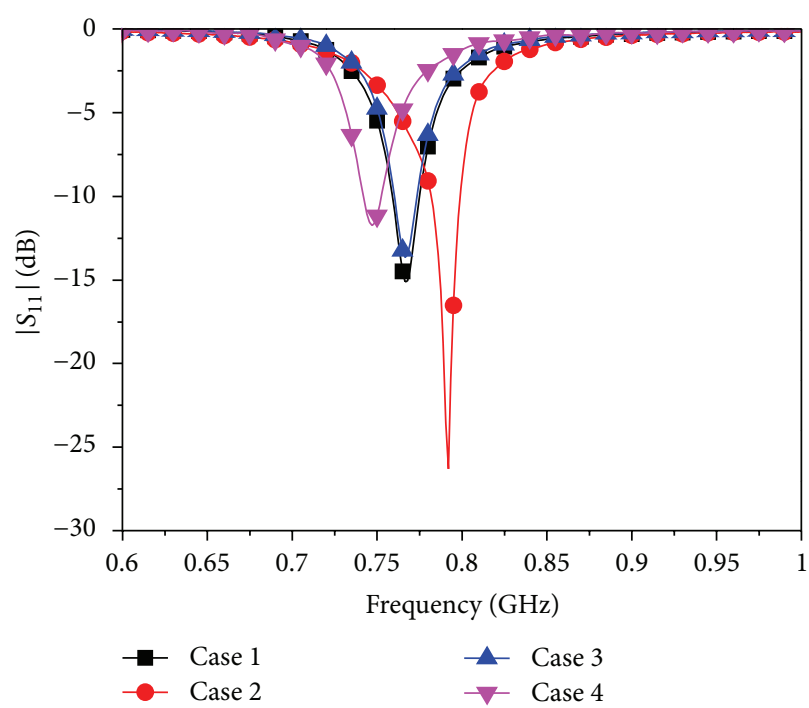

(a)

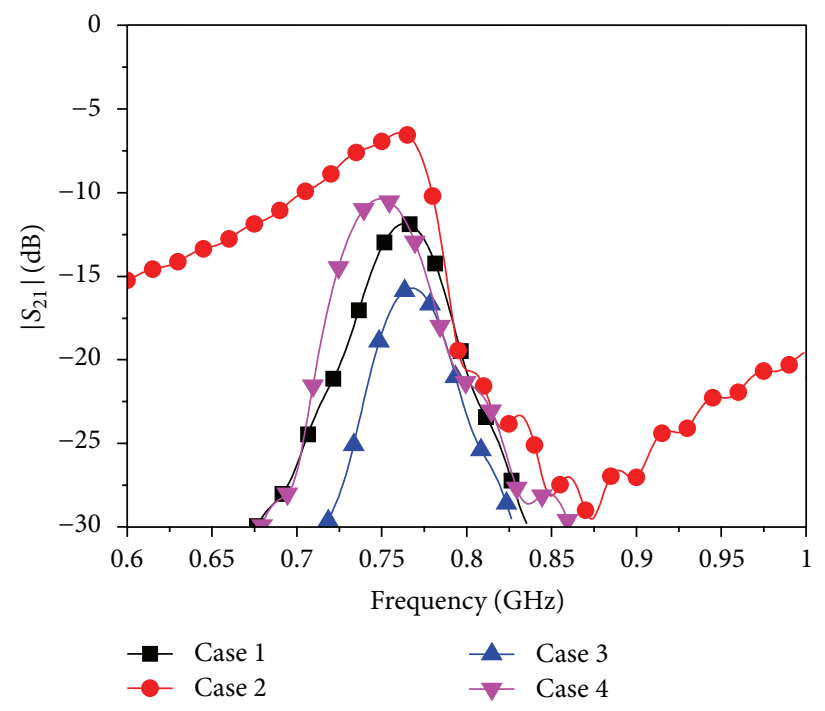

(b)

FIgURE 4: Simulated $S$-parameters; (a) $S_{11}$ and (b) $S_{21}$.
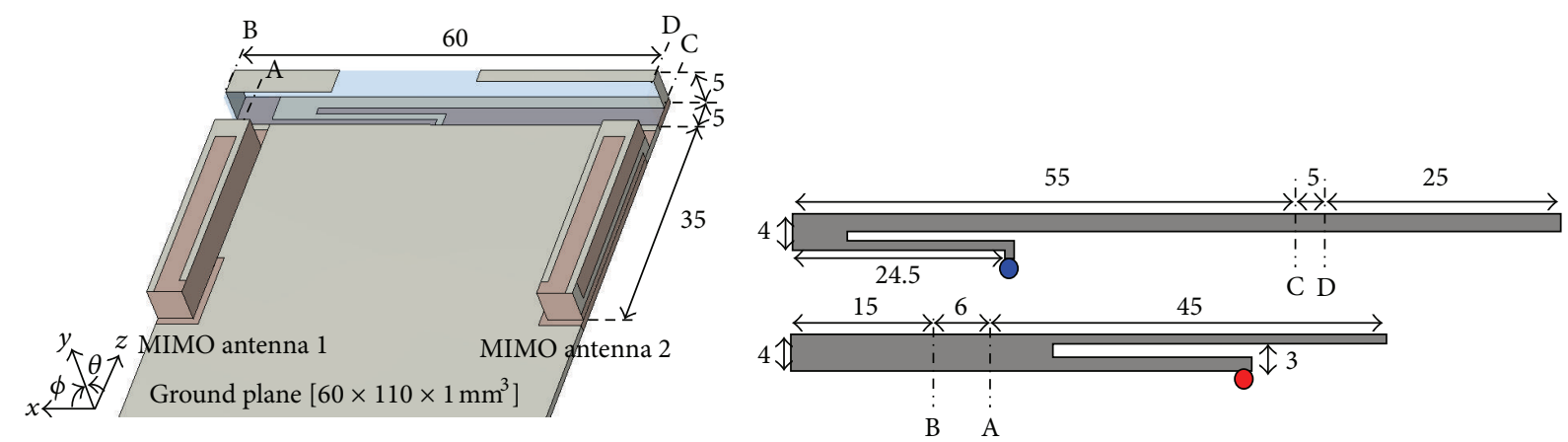

[unit: $\mathrm{mm}$ ]

O Shorting

_.. Folded line

... Folded line

(a)

(b)

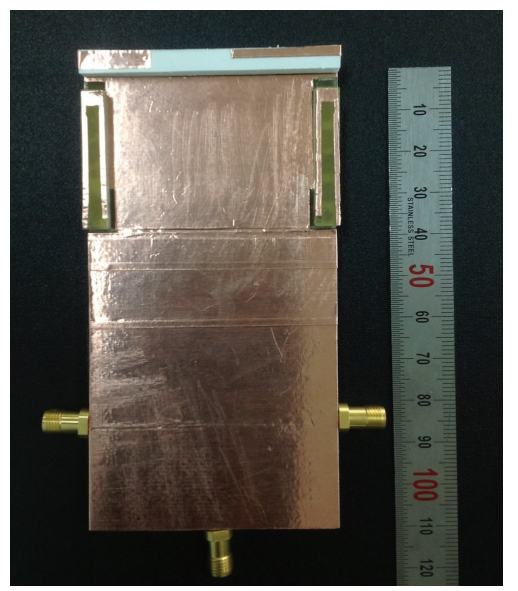

(c)

FIGURE 5: Geometry of the proposed antenna; (a) overall view, (b) detailed view of main antenna, and (c) fabricated antenna. 
TABLE 1: Simulated results for each case.

\begin{tabular}{|c|c|c|c|c|}
\hline \multirow{2}{*}{ Contents } & \multicolumn{4}{|c|}{ Ant. type } \\
\hline & Case 1 & Case 2 & Case 3 & Case 4 \\
\hline Resonant frequency $\left(f_{r}\right)$ & $0.765 \mathrm{GHz}$ & $0.791 \mathrm{GHz}$ & $0.766 \mathrm{GHz}$ & $0.754 \mathrm{GHz}$ \\
\hline Isolation & $11.8 \mathrm{~dB}$ & $6.7 \mathrm{~dB}$ & $15.7 \mathrm{~dB}$ & $10.3 \mathrm{~dB}$ \\
\hline $\operatorname{ECC}\left(\right.$ at $\left.f_{r}\right)$ & 0.52 & 0.78 & 0.19 & 0.81 \\
\hline Arrangement (gap) & Perpendicular (20 mm) & Broadside $(10 \mathrm{~mm})$ & Collinear (50 mm) & Collinear $(10 \mathrm{~mm})$ \\
\hline
\end{tabular}

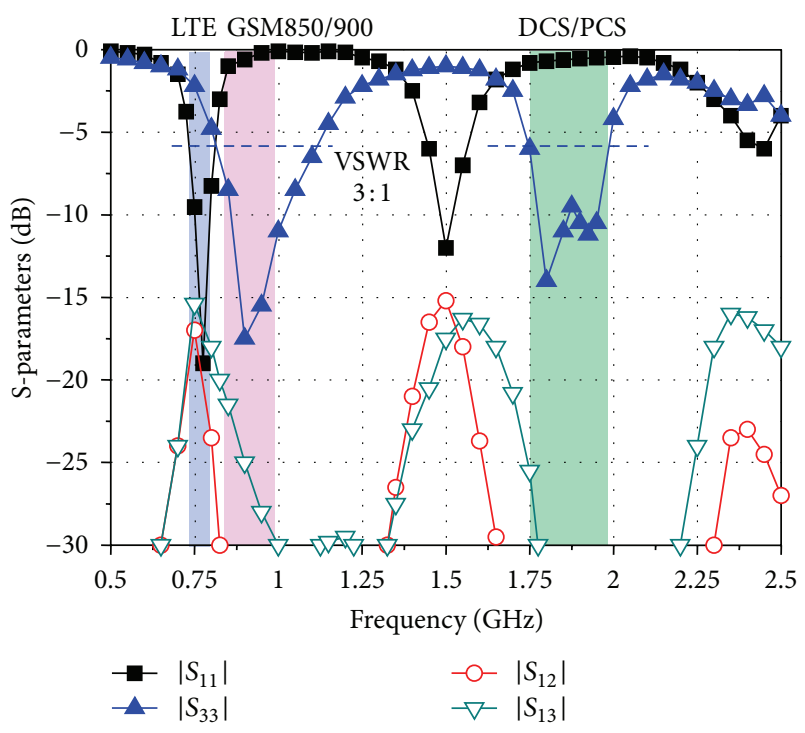

FIGURE 6: Measured $S$-parameters.

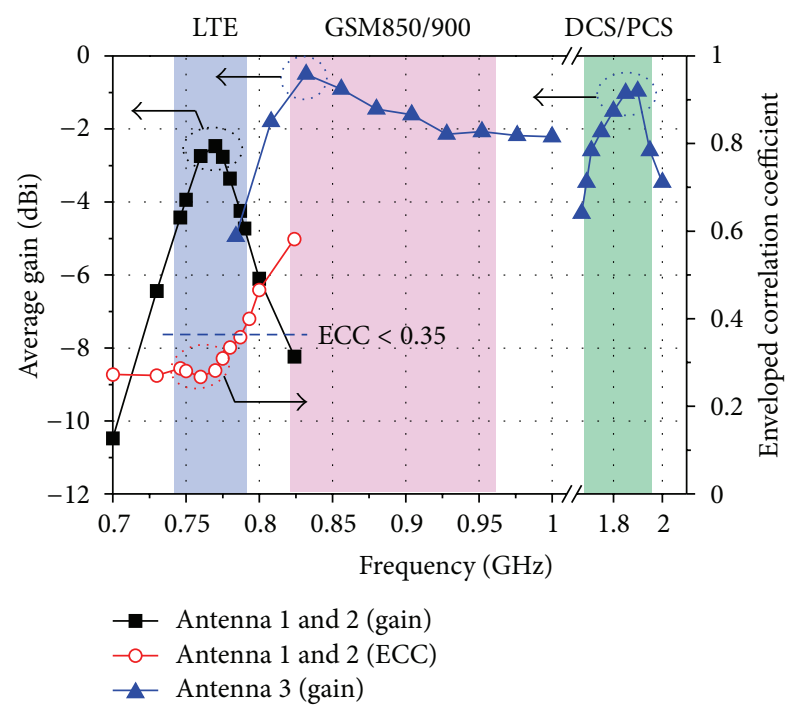

FIgURE 7: Measured average gain and ECC.

narrow area, they operate almost independently. The measured isolation between the two MIMO antennas is higher than $15 \mathrm{~dB}$, and this is generally acceptable for practical MIMO antenna applications in industry. Figure 7 shows the measured average gain and ECC. The proposed antenna has an average gain of more than $-4.3 \mathrm{dBi}$ in the LTE band and

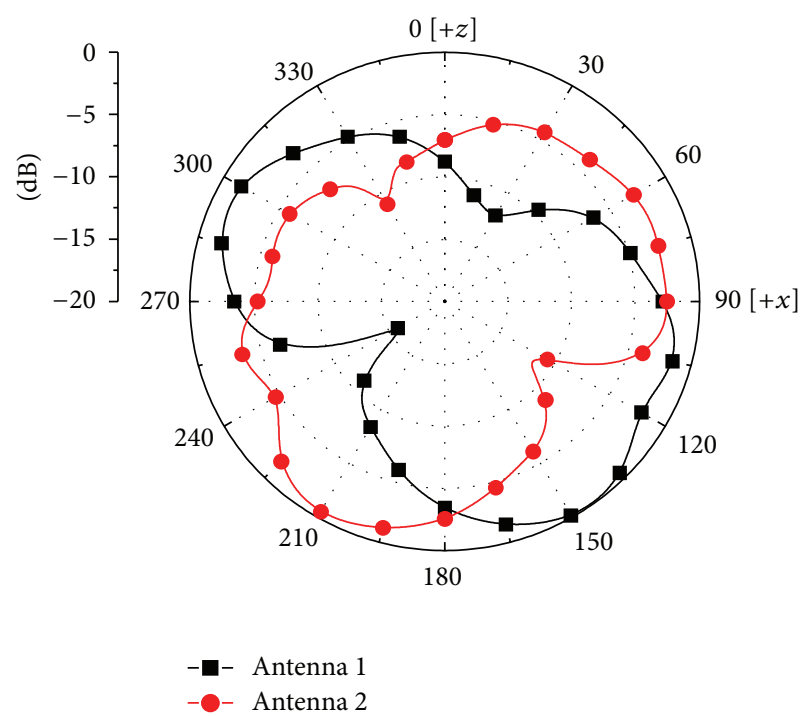

Figure 8: Measured radiation patterns at $766 \mathrm{MHz}$ ( $z x$-plane).

more than $-3 \mathrm{dBi}$ in the GSM850/900 and DCS/PCS bands. Moreover, the proposed LTE MIMO antenna shows a lower ECC $(<0.35)$. Figure 8 shows the measured radiation patterns of two MIMO antennas in the LTE700 band (766 MHz). They have been measured with one antenna excited and the other terminated to a load with $50 \Omega$. The polarizations of the two antennas are orthogonal to each other. Since each MIMO antenna element (PIFA) has both the vertical E-field component (due to current on the radiating element) and the horizontal $E$-field component (due to current on the ground plane), the direction of the compositive E-field can be diagonal. In addition to this, since the horizontal E-field component of each MIMO antenna element is in opposite direction, the polarizations of the two antennas are diagonally orthogonal to each other, as shown in Figure 8. Therefore, these orthogonal radiation patterns and high isolation $(>15 \mathrm{~dB})$ result in a lower ECC $(<0.35)$ which is less than the recommended value of 0.5 [11].

\section{Conclusion}

A compact $\left(5 \times 35 \times 6 \mathrm{~mm}^{3}\right)$ handset MIMO antenna for LTE 700 band applications has been proposed and constructed with two symmetrical PIFAs. Closely packed MIMO antennas were designed, without any additional coupling structures to obtain good isolation. The proposed antenna achieves high isolation $(>15 \mathrm{~dB})$ and low ECC $(<0.35)$ by 
collinearly arranging the E-fields of two antennas in the nearfield region and obtaining diagonally orthogonal radiation patterns.

\section{Acknowledgment}

This research was conducted under a Research Grant from Kwangwoon University in 2013, and this work (Grant no. C0015229) was supported by Business for Cooperative R\&D between Industry, Academy, and Research Institute funded Korea Small and Medium Business Administration in 2012.

\section{References}

[1] G. J. Foschini, "Layered space-time architecture for wireless communication in a fading environment when using multielement antennas," Bell Labs Technical Journal, vol. 1, no. 2, pp. 41-59, 1996.

[2] C. Y. Chiu, C. H. Cheng, R. D. Murch, and C. R. Rowell, "Reduction of mutual coupling between closely-packed antenna elements," IEEE Transactions on Antennas and Propagation, vol. 55, no. 6, pp. 1732-1738, 2007.

[3] M. S. Sharawi, S. S. Iqbal, and Y. S. Faouri, "An $800 \mathrm{MHz} 2 \mathrm{xl}$ compact MIMO antenna system for LTE handsets," IEEE Transactions on Antenna and Propagation, vol. 59, no. 8, pp. 3128-3131, 2011.

[4] A. C. K. Mak, C. R. Rowell, and R. D. Murch, "Isolation enhancement between two closely packed antennas," IEEE Transactions on Antennas and Propagation, vol. 56, no. 11, pp. 34113419, 2008.

[5] A. Diallo, C. Luxey, P. L. Thuc, R. Staraj, and G. Kossiavas, "Study and reduction of the mutual coupling between two mobile phone PIFAs operating in the DCS1800 and UMTS bands," IEEE Transactions on Antenna and Propagation, vol. 54, no. 11, pp. 3063-3074.

[6] J. Byun, J. H. Jo, and B. Lee, "Compact dual-band diversity antenna for mobile handset applications," Microwave and Optical Technology Letters, vol. 50, no. 10, pp. 2600-2604, 2008.

[7] B. Yu, C. W. Jung, H. Lee et al., "Closely mounted compact wideband diversity antenna for mobile phone applications," International Journal of Antennas and Propagation, vol. 2012, Article ID 798046, 6 pages, 2012.

[8] H. Bae, F. J. Harackiewicz, M. J. Park et al., "Compact mobile handset MIMO antenna for LTE700 applications," Microwave and Optical Technology Letters, vol. 52, no. 11, pp. 2419-2422, 2010.

[9] B. Kim, Y. Park, H. Wi et al., "Isolation enhancement of USB dongle MIMO antenna in LTE 700 band applications," IEEE Antennas and Wireless Propagation Letters, vol. 11, pp. 961-964, 2012.

[10] N. G. Alexopoulos and I. E. Rana, "Mutual impedance computation between printed dipoles," IEEE Transactions on Antennas and Propagation, vol. 29, no. 1, pp. 106-111, 1981.

[11] R. G. Vaughan and J. B. Andersen, "Antenna diversity in mobile communications," IEEE Transactions on Vehicular Technology, vol. 36, no. 4, pp. 149-172, 1987.

[12] S. Blanch, J. Romeu, and I. Corbella, "Exact representation of antenna system diversity performance from input parameter description," Electronics Letters, vol. 39, no. 9, pp. 705-707, 2003.
[13] H. Rhyu, J. Byun, F. J. Harackiewicz et al., "Multi-band hybrid antenna for ultra-thin mobile phone applications," Electronics Letters, vol. 45, no. 15, pp. 773-774, 2009. 

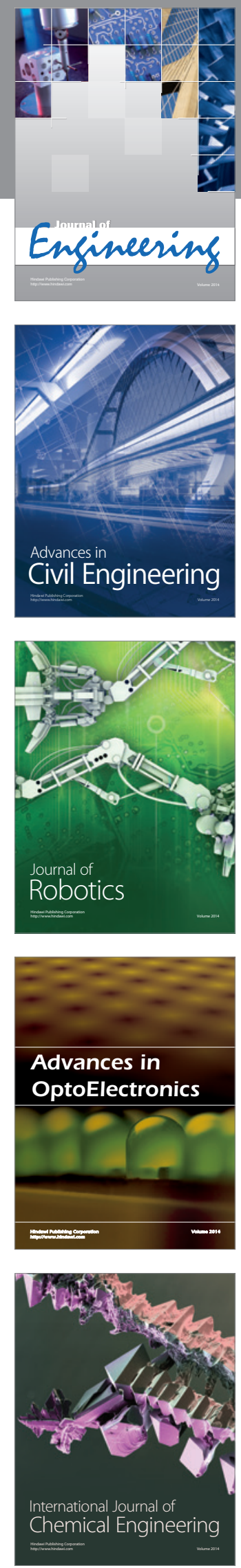

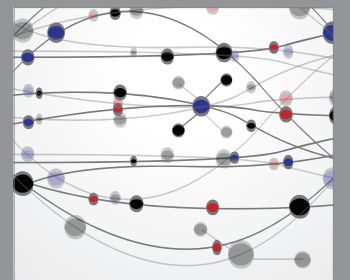

The Scientific World Journal
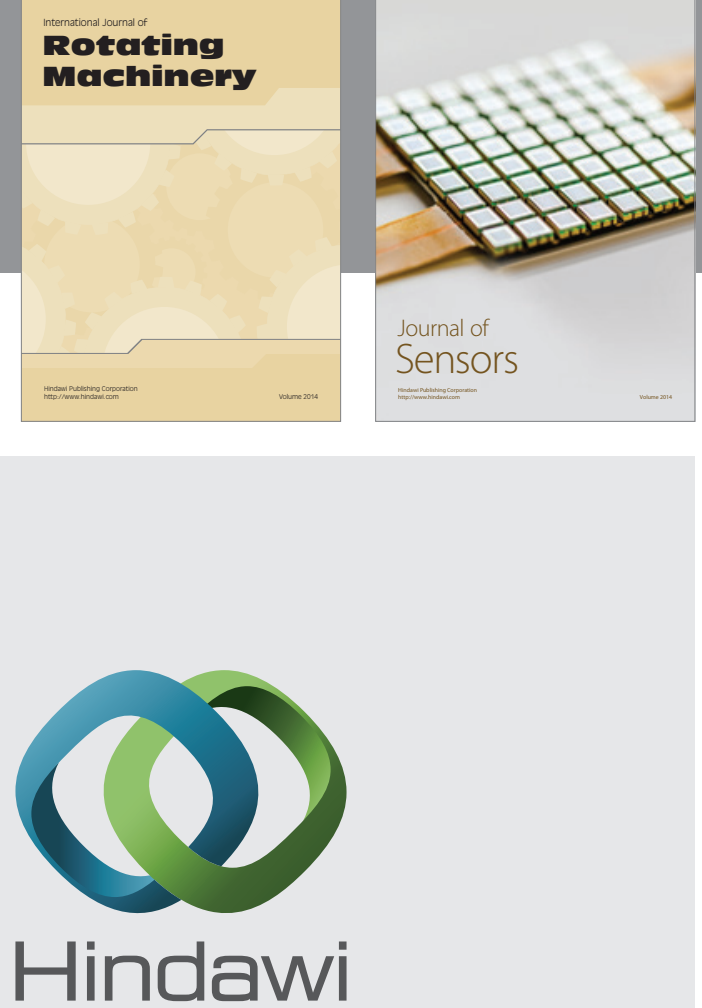

Submit your manuscripts at http://www.hindawi.com
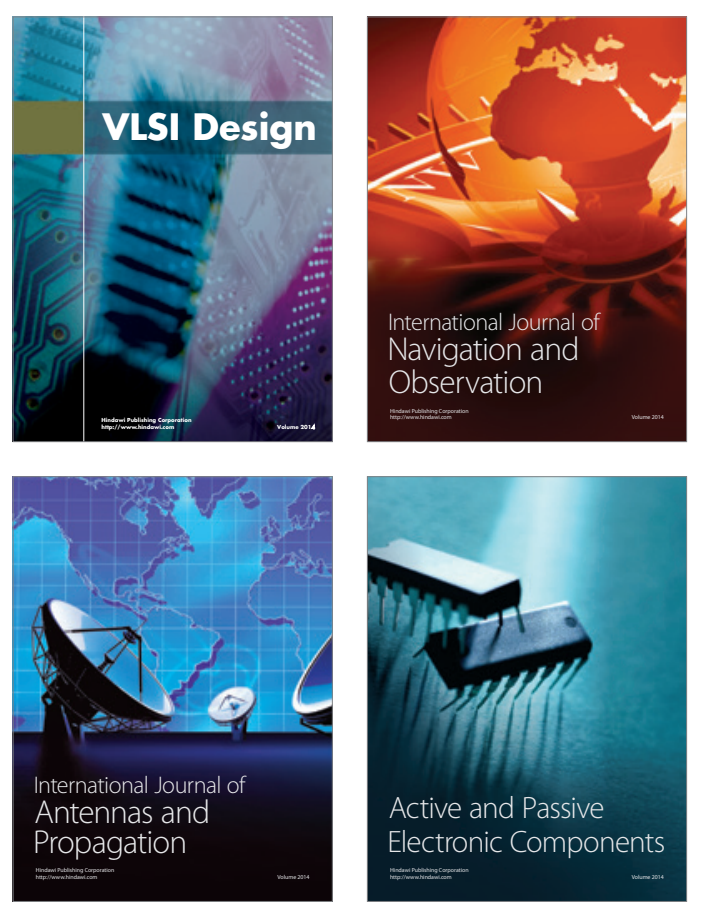
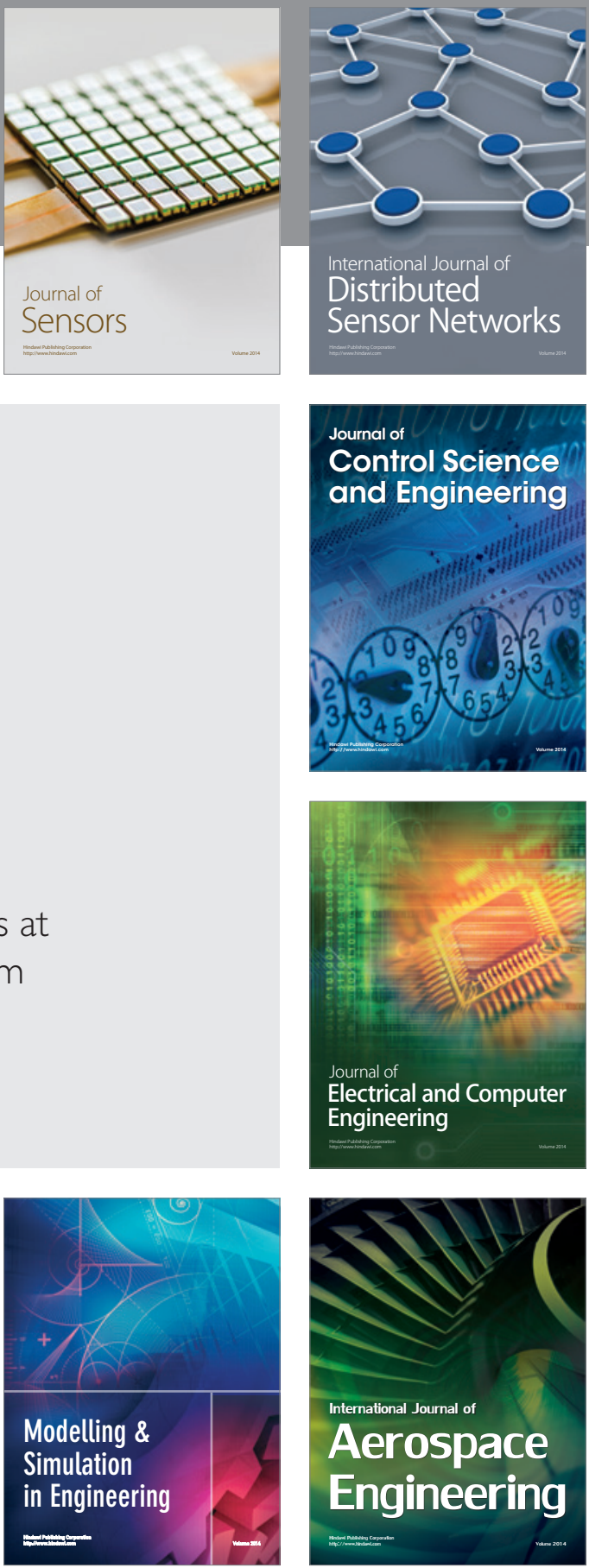

Journal of

Control Science

and Engineering
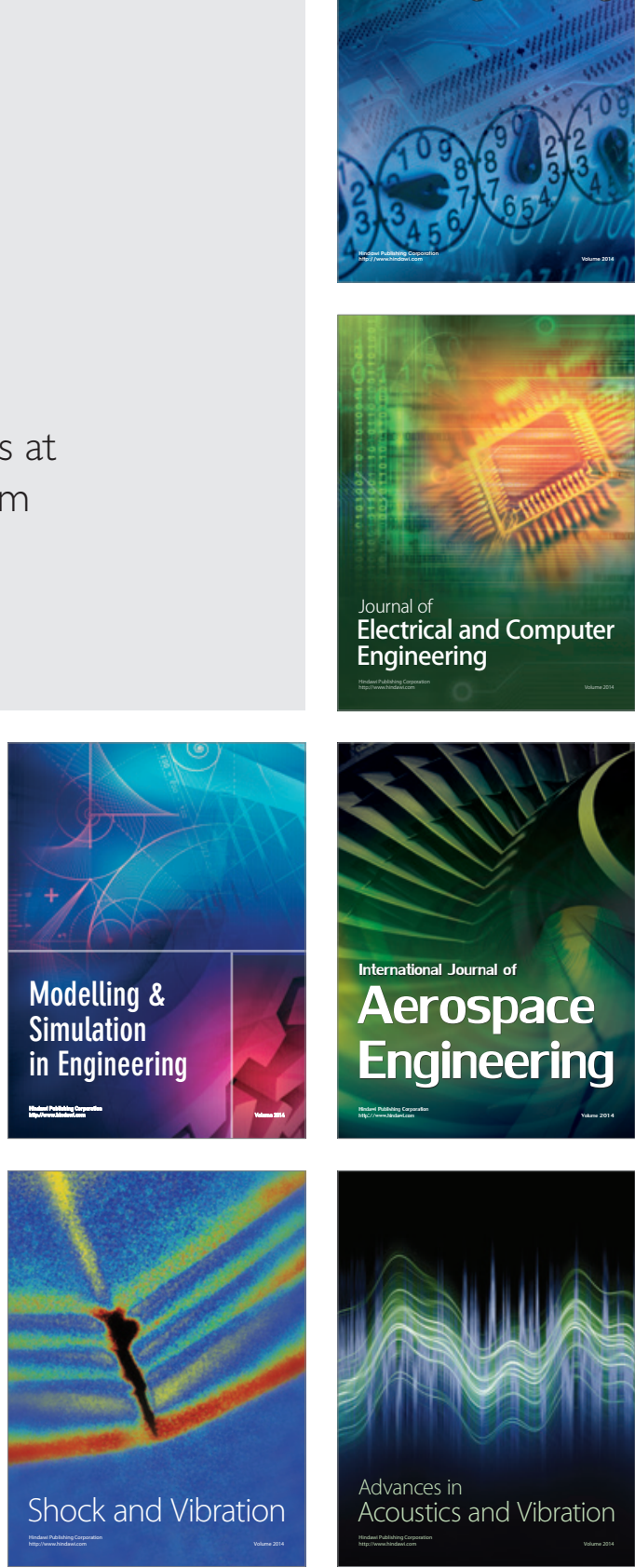